
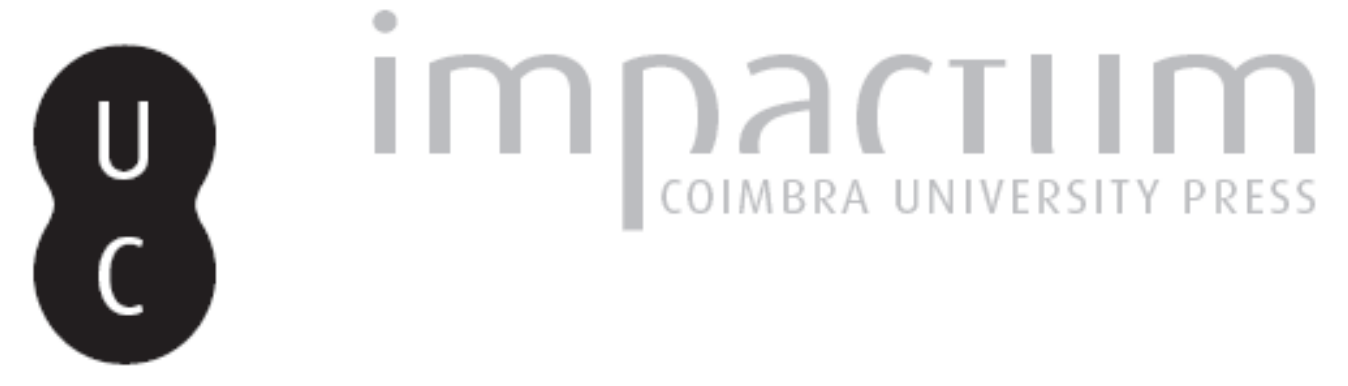

\title{
Antero, açoriano: vozes em volta
}

Autor(es): Bettencourt, Urbano

Publicado por: Imprensa da Universidade de Coimbra

URL persistente:

URl:http://hdl.handle.net/10316.2/43747

DOI:

DOI:https://doi.org/10.14195/2183-8925_13_10

Accessed : $\quad$ 26-Apr-2023 09:15:09

A navegação consulta e descarregamento dos títulos inseridos nas Bibliotecas Digitais UC Digitalis, UC Pombalina e UC Impactum, pressupõem a aceitação plena e sem reservas dos Termos e Condições de Uso destas Bibliotecas Digitais, disponíveis em https://digitalis.uc.pt/pt-pt/termos.

Conforme exposto nos referidos Termos e Condições de Uso, o descarregamento de títulos de acesso restrito requer uma licença válida de autorização devendo o utilizador aceder ao(s) documento(s) a partir de um endereço de IP da instituição detentora da supramencionada licença.

Ao utilizador é apenas permitido o descarregamento para uso pessoal, pelo que o emprego do(s) título(s) descarregado(s) para outro fim, designadamente comercial, carece de autorização do respetivo autor ou editor da obra.

Na medida em que todas as obras da UC Digitalis se encontram protegidas pelo Código do Direito de Autor e Direitos Conexos e demais legislação aplicável, toda a cópia, parcial ou total, deste documento, nos casos em que é legalmente admitida, deverá conter ou fazer-se acompanhar por este aviso.

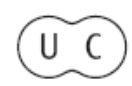


REVISTA DE HISTÓRIA DAS IDEIAS 13

\section{Antero de Quental}

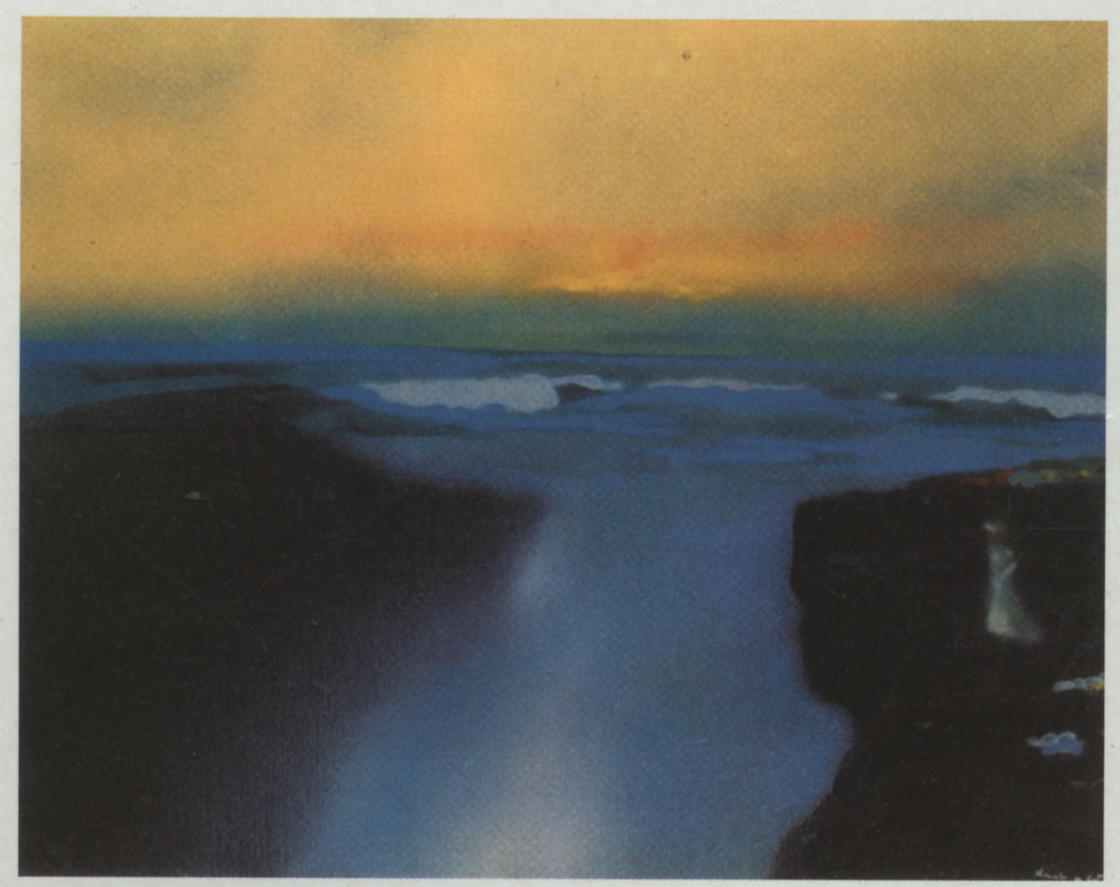

INSTITUTO DE HISTÓRIA E TEORIA DAS IDEIAS FACULDADE DE LETRAS

COIMBRA 1991 


\section{ANTERO, AÇORIANO \\ Vozes em Volta}

É possível que, por si só, um título como "Redenção" (sob o qual, aliás, Antero reúne dois sonetos) não seja capaz de evocar muita coisa em termos de autores açorianos e do seu jogo de inter-relacionamentos textuais; mas o caso já muda de aspecto se considerarmos o último terceto do primeiro desses sonetos:

"E eu compreendo a vossa língua estranha,

Vozes do mar, da selva, da montanha...

Almas irmãs da minha, almas cativas!"

que aparece como epígrafe ao livro de outro açoriano, o poeta Roberto de Mesquita (1871-1923), que aí foi buscar ainda o título para o seu livro, Almas Cativas, publicado postumamente em 1931. Mesquita detecta em Antero, particularmente notercetoem questão, os elementos que poderiam aproximar o autor dos Sonetos $\left(^{(}\right)$da sua própria cosmovisão de poeta desterrado e confinado aos limites do cárcere ilhéu e cujo diálogo (ou simples interpelação) com uma natureza animizada surge como efeito e como tentativa de superação de uma

* Universidade dos Açores.

(') Para uma perspectiva sobre a passagem do pampsiquismo de Antero a Mesquita, veja-se Manuel Cândido, Antero e Roberto de Mesquita, Col. Opúsculos, 3, Vila Franca do Campo (Açores), Editorial Ilha Nova, 1986. 
irremediável solidão atlântica; ora isto torna-se tanto mais significativo (ou perturbante, se se preferir) quanto é certo que Mesquita, no dizer de Nemésio o primeiro poeta que exprime alguma coisa de essencial na condição humana tal como ela se apresenta nas ilhas dos Açores ( ${ }^{2}$ ), vai socorrer-se, para pórtico da sua obra, do texto de um poeta em relação ao qual continuam a colocar-se dúvidas e interrogações quanto à natureza ou à verdadeira dimensão do fundo açoriano da sua obra - ao lado de opinióes que apontam sobretudo para marcas indirectas, difusas da insularidade na sua obra, torna-se igualmente possível encontrar quem as negue mesmo a esse nível $\left({ }^{3}\right)$.

Vitorino Nemésio (mais uma vez) pode considerar-se um caso sintomático neste processo de equacionamento da presença dos Açores na obra de Antero. Num texto de 1928 e já hoje clássico $\left({ }^{4}\right)$, apesar de afirmar que inutilmente nela se procurará côr, forma, externidade que. nos revelem o pequeno mundo açoriano com o seu físico e os seus hábitos, Nemésio não deixa de reconhecer que toda a poesia anteriana está impregnada de açorianismo. A contradição entre as duas asserçōes $\varepsilon$ apenas aparente, porquanto Nemésio situa essa presença menos ao nível de superfície que ao de uma matriz profunda que modela a atitude de Antero e o ton da sua obra, a um temipo filosófica e poética. Poder-se-á dizer, pelo contexto mais vasto em que as citações anteriores se enquadram, que há, da parte de Nemésio, um esforço para encontrar uma solução que harmonize e concilie, em Antero, a questão do regionalismo (açoriano) e do universalismo, articulando um e outro de forma eficaz, não redutora. E já não era a primeira vez que a questão se colocava, embora com respostas diferentes.

${ }^{(2)}$ Vitorino Nemésio, "O Poeta e o Isolamento: Roberto de Mesquita" in Conhecimento de Poesia, $2^{2} \mathrm{ed}$., Lisboa, Editorial Verbo, 1970 . O texto sobre Mesquita foi inicialmente publicado no no 6 da Revista de Portugal, Janeiro de 1939.

( $\left.{ }^{3}\right)$ Como exemplos deste último grupo, podem citar-se os casos de Macedo Fernandes (em depoimento de 1980 republicado por Onésimo Teotónio Almeida, $A$ Questão da Literatura Açoriana, Col. Gaivota, $n^{\circ} 32$, Angra do Heroísmo, SREC, 1983) e ainda, mais recentemente, o de Arnaldo Saraiva: "parece-me que o pensador Antero, o poeta Antero tem poucas marcas açorianas típicas" (entrevista ao jornal Açoriano Oriental, 3/11/1990).

$\left({ }^{4}\right)$ "O Açoriano e os Açores", publicado em Sob os Signos de Agora, Coimbra, Imprensa da Universidade, 1932, pp. 115 a 141.

Texto "clássico", mesmo que sujeito a questionamentos e a desenvolvimentos; veja-se, a propósito, Onésimo Teotónio Almeida, Açores, Açorianos e Açorianidade, Ponta Delgada, Signo, 1989, pp. 31 a 40. 
Anos antes, em 1921, Aristides da Mota pronunciara-se publicamente $\left(^{5}\right)$ sobre o carácter universal dos Sonetos e de Antero, recusando a possibilidade de qualquer apropriação de cariz nacional, menos ainda regional. No final do artigo, e como elemento para a reconstituição da psicologia de Antero, Aristides da Mota acrescentava uma lista de 40 sonetos em que aparecem as imagens do mar e do vento ; e concluía: "eis como Antero, que não é certamente um poeta regional, se vincula à sua terra pelos mais rudimentares, primitivose obscuros, mas os mais activos elementos do fundo irreductivel da sua mentalidade - as impressões da infância e da primeira mocidade".

No ano seguinte, Luís Ribeiro ${ }^{6}$ ) retoma as pistas levantadas pelo artigo anterior e alarga o seu campo de observações às Odes Modernas; reconhecendo que "é nas imagens de que [Antero] se serve para dar relevo [às ideias e aos sentimentos] que temos de ir procurar a possivel influência do meio açoriano", Luís Ribeiro não se limita ao mero levantamento de ocorrências, como fizera Aristides da Mota, e avança já alguns elementos sobre a carga simbólica que aí adquirem o mar e o vento - e, para lá destas, não vê outras referências que possam atribuir-se à influência regional.

Se bem que não precisemos de remeter para o domínio do curioso o facto de nem Aristides da Mota nem Luís Ribeiro provirem, em termos de formação científica, do campo dos estudos literários, não devemos deixar de referir o estatuto de que as suas observações passaram a desfrutar, desenvolvidas mais tarde por Ruy Galvão de Carvalho, que consegue até ver as Sete Cidades do soneto "Idílio"! ( $\left.{ }^{7}\right)$. Ora, mesmo admitindo a pertinência de tais observações, importa notar que elas enfermam de algumas limitações capazes de condicionar a leitura: por um lado, descurando a hipótese de um sistema simbólico construído sobre os quatros elementos primordiais, acabam por não considerar a presença, no texto anteriano, dos elementos em falta (o fogo e a terra, já que o mar e o vento recobrem, respectivamente, a água

(5) "Alguns apontamentos sobre Antero", Correio dos Açores, 17/4/1921.

(6) "O regionalismo açoreano na obra de Antero de Quental", Correio dos Açores, 10/9/1922.

( 7 ) "A insularidade na poesia de Antero de Quental" in Antero de Quental - Novos Ensaios, Col. Açorense, Vila Franca do Campo (Açores), Editorial Ilha Nova, 1985, pp. 55-64. 
e o ar); por outro lado, deixam por explicar a razão por que o fogo, embora em menor número de ocorrências, não há-de constituir marca tão açoriana como o vento.

Nemésio tem, nesse texto de 1928 , a consciência da reduzida ou nula presença de traços externos que permitam falar de um rasto palpável de açorianidade na poesia anteriana. Daí, a rede de conexões simbólicas e de analogias por ele aduzidas e que permitiriam uma leitura insular de Antero, em cuja maneira de ser mais profunda estaria impressa a marca indelével do mar: "a alma do ilhéu exprime-se pelo mar. (...) As ilhas são o efémero e o contingente: só o mar é eterno e necessário".

No contraste que lhes estabelece Nemésio, ilhas e mar podem passar aqui como os dois pólos da dualidade Finito e Infinito, espaço fechado e espaço ilimitado, pólos geradores de uma tensão capaz de levar o homem ilhéu a projectar-se, mesmo a nível imaginário, para lá da estreiteza dos horizontes e dos limites imediatos. Ese sobrepusermos os pares Ilhas/Mar e Efémero/Eterno ao par anteriano Ilusão/Absoluto, talvez possamos compreender melhor o pensamento de Nemésio quando, após estabelecer semelhanças entre o espírito humanado e o mar e incidir na influência deste sobre o homem, afirma que o açorianismo de Antero residirá no facto de a sua natureza de ilhéu marcado pela presença multímoda do mar explicar simultaneamente o pessimismo, a inquietação e o anseio de liberdade que o caracterizam $\left({ }^{8}\right)$ possivelmente, aquilo a que Antero chamou a tristezalduma ânsia impotente de infinito $\left({ }^{9}\right)$.

Anos mais tarde, Nemésio retomará está questão $\left({ }^{10}\right)$ mas aqui a

$\left({ }^{8}\right)$ Em carta de 1880 enviada a João Lobo de Moura (por essa altura a residir em Vila Franca do Campo), escreve Antero: "Diga-me também de si. Que efeito lhe fezo mar, o velho misterioso? E essas terras semi-tropicais, com os aspectos singulares e chineses, o seu "grande em ponto pequeno" e a sua vegetação sombria?" (Antero de Quental, Cartas I, Org., Introd. e Notas de Ana Maria Almeida Martins, Lisboa, Universidade dos Açores e Editorial Comunicação, 1989, p. 486).

Todas as minhas referências às cartas de Antero remeterão para esta edição em dois volumes.

(9) "O convertido", in Sonetos, Org., Pref. e Notas de António Sérgio, $5^{2}$ ed., Lisboa, Livraria Sá da Costa, 1976, p. 120.

$\left({ }^{10}\right)$ "Nota sobre Antero", Aventura, Revista de Cultura, n. ${ }^{\circ}$ 2, Lisboa, Agosto, 1942.

Para lá da imprecisão que é dar o nascimento de Antero como ocorrido na "casa do Ramalho" (Solar do Bom Sucesso), o texto mereceria transcrição integral: pela perspectiva de Nemésio sobre Antero, pela (feliz) incapacidade de falar dos outros sem falarde si e ainda pela linguagem, condensadac transbordante daquela afectividade tão 
tranquilidade do texto atrás referido cede o passo a um desdobrar de perplexidades e interrogações. Entre os dois textos, porém, $o$ mar constitui-se ainda o elemento de ligação e Nemésio vê nele o núcleo residual cujo apelo importaria perscrutar e analisar no âmbito de uma vida de Antero que, por hipótese remota, ele viesse a escrever; hipótese remota, mais do que isso impossível, confessa Nemésio:

"No fundo, acabo sempre por recuar diante de uma vida de Antero por um motivo surdo, ressentido. É o meu desespero de o não ver exprimir deliberadamente a nossa condição, apesar - de ter assinado um dia Antero Insulano. É o desgôsto de se ter perdido, na sua rara cabeça e naquele coração como nenhum, a grande ocasião de um ilhéu dos Açores identificado com as ilhas, aderindo àquilo no sangue da sua obra.

Mas Antero escapa-se-me sempre pelo olímpico portal da sua universalidade."

Nemésio volta a equacionar aqui o dualismo universal/regional, expresso em termos de olímpico portal e pequena etiqueta açoriana $\left({ }^{11}\right)$, dualismo para o qual o texto de 1928 parecia ter encontrado uma saída satisfatória na exemplaridade de um Antero progressivamente despojado e liberto da temporalidade e da matéria até chegar ao encontro com o fundo irredutivel da sua própria humanidade, esta, sim, verdadeiramente essencial e susceptível de determinar o combate de Antero e a sua visão das questões particulares sempre em termos de uma visão mais vasta do mundo e da Humanidade. Isto, porém, não impediu Nemésio de, nesta "Nota sobre Antero", formular uma série de questões e de dúvidas que se prendem com a ausência de um açorianismo explícito e assumido na obra do poeta micaelense:

"Porque é que Antero não exprimiu isso que foi a sua agonia secreta, em termos diferentes de uma tentativa metafísica de Icaro? Porque é que ... (A estúpida pergunta! Eu ia a dizer: porque é que ele não foi romancista? criador de pequenos fantasmas verosímeis e familiares, habitando os Açores, modelando a sua dor humana nos limites daquilo e com a forma de viver e penar daquela gente? Mas jámenos estúpido seria perguntar porque é que ele atrofiou o grande poeta que havia dentro de

própria de Nemésio ao falar dos Açores.

(') Mais do que Antero a repelir esta etiqueta, seriam "os seus admiradores e comentadores do continente" que nunca a perdoariam a Nemésio - confessa este. 
si com a secura conceptual dos seus temas em série - A Ideia, Elogio da Morte... Ah! O poeta frustrado gritaria o nosso isolamento! Os Açores acabavam por ter voz)".

As interrogações de Nemésio devem entender-se dentro de um contexto próprio que respeita não apenas ao seu autor e à açorianidade exacerbadamente assumida de quem escreveu que "os naturais dos sítios são como os criminosos, voltam ao lugar do delito" $\left({ }^{12}\right)$, mas também ao tempo em que elas foram formuladas - por essa época andava Nemésio às voltas com o tal romance que Antero não escrevera e criava os pequenos fantasmas verosímeis e familiares que podiam chamar-se apenas Ti Amaro da Mirateca, Cândia Furoa, ou ter Clark Dulmo ou Garcia como nome de família. Talvez isto ajude a explicar a inquietação que as perguntas de Nemésio traduzem e a ser compreensivos para com esta atitude de alguma injustiça que é julgar o passado não tanto à luz dos seus próprios limites mas já em função dos apetrechos e dos elementos de que dispomos num tempo que é o nosso.

A presença (ou não) da açorianidade na obra de Antero é, com efeito, uma questão relativa, estabelecida por contraste e, de certa forma, formulada a posteriori - isto é, ela só se coloca a partir do momento em que essa açorianidade se torna manifestamente explícita e consciente noutros escritores; e, se, em termos cronológicos, aquele que se encontra mais próximo de Antero é Roberto de Mesquita, importa reter que a diferença etária entre ambos é de cerca de trinta anos: em 1871, quando Mesquita nasce, já Antero publicara as Odes Modernas e escrevera parte significativa dos sonetos. Dizer isto é apenas uma forma de chamar a atenção para o lento caminhar das ideias até ao seu amadurecimento pleno e à sua plena manifestação em distintos contextos culturais e sociais e em virtude igualmente de factores de ordem individual que, no conjunto, justificam que esta ou aquela obra sejam assim e não de outra forma. Se o próprio termo açorianidade, criado por Nemésio, traz como data de cunhagem o ano $1932\left({ }^{13}\right)$, também poderíamos perguntar-nos: porquê só nesse ano? porquê Nemésio e não outro? Brandão, por exemplo. Perguntas re-

('2) Vitorino Nemésio, Corsário das Ilhas, 2." ed., Pref. de António M. Bettencourt Machado Pires, Amadora, Liv. Bertrand, 1983, p. 125.

$\left({ }^{13}\right)$ O neologismo surge exactamente como título de um artigo publicado na revista Insula, $\mathbf{n}^{\circ}$ 7-8, Ponta Delgada, Julho/Agosto, 1932. 
tóricas (ou estúpidas, também elas), depois que Nemésio explicitou o enquadramento em que inventou o vocábulo, isto é, na sequência da leitura de ensaístas espanhois, entre eles Pi y Margall e Unamuno, sobre cujos termos hispanidad e argentinidad Nemésio confessa ter decalcado o seu $\left({ }^{14}\right)$.

Em suma, e concluindo, Antero chegava cedo de mais no tempo, para que se pudesse exigir-lhe uma assumida consciencialização da sua condição de açoriano; a descoberta dos Açores estava ainda para acontecer.

Há, todavia, outros factores que poderão ter contribuído para desviar o rumo de Antero, orientando-o num sentido mais vasto de preocupação com os problemas do país e da Humanidade e deles se ocupou já em particular António M. B. Machado Pires ( ${ }^{15}$ ); o Programa das Conferências Democráticas, para além de uma crença optimista na transformação social, é, na verdade, perfeitamente revelador desse espírito inquieto e atento às grandes preocupações intelectuais do seu tempo e preocupado em fazer com que o país acerte o passo pelo ritmo da Europa culta.

É possível que o deslumbramento, o desnorteamento também, de Antero perante as encontradas correntes do espírito moderno que vinham repercutir-se em Coimbra e motivam a revolução intelectual e moral de que ele fala na carta a Wilhelm Storck $\left({ }^{16}\right)$ tenha ajudado a relegar para um plano secundário a província remota e imersa no seu sono histórico que ele deixara no atlântico; o confronto dos dois mundos foi seguramente desfavorável a este último, mas talvez tenha faltado aqui, entre Antero e a Ilha, uma relação afectiva mais profunda e saudável, uma paixão até, capaz de motivar a viagem de retorno e a

(14) Vitorino Nemésio, Açores: Actualidade e destinos, Angra do Heroísmo, Edit. Atlântida, 1975, pp. 35-36.

(15) "Universalismo e identidade Nacional em Antero de Quental" in Onésimo Teotónio Almeida, Da Literatura Açoriana - Subsídios para um Balanço, Col. Gaivota, $n^{\circ} 50$, Angra do Heroísmo, SREC, 1986. O volume reúne as comunicações apresentadas ao I Simpósio sobre Literatura Açoriana realizado na Universidade de Brown, Providence, EUA, em Abril de 1983.

António M. B. Machado Pires resume a três as grandes questões do pensamento anteriano: a questão metafísica, a questão social e a questão nacional.

$\left({ }^{16}\right)$ Antero de Quental, Cartas II, p. 833 ss.

Esta é a chamada carta autobiográfica, escrita em S. Miguel a 14/5/1887, uma das várias endereçadas a Storck. 
fixação à Ilha e a sua re-invenção através da Palavra.

Uma leitura das Cartas poderá fornecer-nos alguns dados para a compreensãodo que tenha sido, efectivamente, essa relação, os diversos matizes, por vezes contraditórios, de que ela se revestiu. Sendo essa uma leitura em aberto cujas conclusões finais ainda aguardam oportunidade, gostaria, no entanto, de dedicar aqui alguma atenção ao que transparece do grupo de cartas escritas dos Açores em 1887, durante o período em que cá permaneceu para tratar de assuntos relativos à sua irmã Maria Ermelinda; com destinatários di versos, mas em grande parte dirigidas a Oliveira Martins, essas cartas, no total de catorze, foram escritas entre 12 Março e 15 de Setembro e todas em S. Miguel, à excepção de uma enviada a Alberto Sampaio e redigida em Angra a 16 de Julho.

Se há um ponto comum a parte significativa dessas cartas, ele consistirá, sem dúvida, na estranheza que Antero manifesta pelo facto de sentir-se bem na sua terra... Existira, na verdade, da parte do poeta o temor de que uma eventual má viagem de barco pudesse vir a ter uma influência nefasta na mudança de ambiente, mas nem mesmo a felicíssima viagem deu azo a grandes manifestações de efusão pelo regresso à ilha ; o tom em que Antero dá conta disso é pouco menos que lacónico: "Não sei porquê, tem-me agora agradado esta terra" - escreveu ele a sua irmã Ana, em 12 de Março; e três dias depois, em carta a Oliveira Martins: "Tive um certo prazer em tornar a ver a minha terra, ainda que não sei porquê, e talvez só por instinto, pois deve haver uma relação profunda entre o homem e a terra em que nasceu e se criou".

Talvez essa relação profunda fosse demasiado profunda, isto é, distante, para ter acesso ao plano de uma expressão mais acentuada e intensa e possa justificar o grau de distanciação com que Antero se refere às ilhas, pitorescas bastante (mas às quais falta o céu claro do continente). E mesmo as referências ao clima açoriano como $o$ clima pátrio e à Ilha de S. Miguel como a [sua] pátria não chegarão para anular a sensação de que falta algo de fortemente emotivo a esta relação entre Antero e a Ilha. De resto, a essa data, o poeta vivia já obcecado pela doença que cada vez mais o atormentava e, como as cartas comprovam, paira sobre ele o fantasma ameaçador do clima açoriano, com a sua hostilidade, e o receio dos efeitos perniciosos que poderá ter sobre a sua abalada saúde. E, se da parte de Antero se nota, por vezes, 
uma certa réstia de expectativa e esperança (talvez mesmo um ténue optimismo), o que transparece, por outras, é a confissão de quem não confia nas primeiras impressões, aparentemente benéficas; assim se compreenderá a insegurança e a instabilidade de quem afirma que "gostaria de [se] fixar aqui definitivamente" (15/3/87), para logo escrever: "comonão me fio nele [clima], conto regressar ao continente tão depressa tenha resolvido as dificuldades que aqui me trouxeram" (29/3/87). Esta oscilação pendular de um homem incapaz de prender-se demasiado a um lugar e que só estaria bem noutro lado, algures, traduzirá muito possivelmente a expressão de Nemésio ao afirmar que Anterofoi, de certa forma, um desenraizado $\left({ }^{17}\right)$ : desprendido, sempre errante, em permanente Busca - daí também a impossibilidade de fixar amarras na temporalidade e na matéria sensorial de uma Ilha.

Cinquenta anos decorridos após a "Nota sobre Antero", ter-se-ão já apaziguado as águas inquietas do questionamento de Nemésio; e o tempo terá permitido concluir que, se a ausência da etiqueta açoriana não diminui a estatura da obra de Antero, a sua ostensiva presença na obra de Nemésio não constitui um obstáculo à universalidade e à grandeza desta última.

(17) "O Açoriano c os Açores", in ob. cit., p. 139. 